\title{
EVALUATING THE EFFECTS OF CHANGE IN INPUT RATIO OF N: P: Si TO COASTAL MARINE ECOSYSTEM
}

\author{
Akira HARASHIMA ${ }^{1}$ \\ ${ }^{1}$ Chief of Marine Environment Laboratory, Dept. of Water and Soil Environment, \\ National Institute for Environmental Studies \\ (16-2, Onogawa, Tsukuba, Ibaraki 305-8506, Japan) \\ E-mail: harashim@nies.go.jp
}

\begin{abstract}
While the loadings of nitrogen $(\mathrm{N})$ and phosphorus $(\mathrm{P})$ are enhanced by the human activities, dissolved silicate (DSi) supplied by natural weathering of minerals tends to be trapped in the eutrophicated still waters such as dammed reservoirs, which are also increasing globally. The consequent change in the N: P: Si stoichiometric ratio of the river water flowing into the coastal sea may be advantageous to flagellates (nonsiliceous and potentially harmful) but not to diatom (siliceous and mostly benign). This is the "silica deficiency hypothesis". We try to develop it further to the "extended silica deficiency hypothesis" as follows. While the diatoms effectively draw down the substances from the upper layer with their sinking after the spring bloom (biological pump), other algae do not. This will cause the retention of the surplus nutrients and biogenic substances in the upper layer and lead further to eutrophication of upper layer substantially. To verify this hypothesis, a simplified marine ecosystem model was developed taking the nutrient stoichiometry and differential behaviors of algae into account based on the comparison with the existing field monitoring results of four aquatic continua, where various types of silica decline are uncertain. Although, this study is still in the stage of improvement, the preliminary results infer that above hypothesis could be verified with the consideration of the behavioral characteristics of algae as well as the stoichiometric consideration. Sinking response to the nutrient depletion, which is specific to each algal group, is one of possible factors.
\end{abstract}

Key Words : aquatic continuum, N:P:Si ratio, algal composition, biological pump, MSFT model

\section{INTRODUCTION}

Among several hypotheses on the global environmental changes, exists the "silica deficiency hypothesis", which infers the teleconnection between the change in the N: P: Si ratio in the river waters and the shift of the basis of the marine ecosystem from the dominance of diatoms (siliceous) to that of the non-diatom algae (non-siliceous). The former is basically benign; the latter includes the dinoflagellates, some of which cause HABs (harmful algal blooms). This hypothesis originates from the earlier works on the general importance of Si process in the coastal marine environment ${ }^{1)}$ and has been developed by further consideration on the effects of land-use ${ }^{2)}$ and the still water effects of the artificial reservoirs with $\mathrm{N}$ and $\mathrm{P}$ inputs ${ }^{3),}{ }^{4)}$. $\mathrm{A}$ field experiment showed that the dominant algae changed from diatom to non-diatom algae when DSi is less
IDB (Irongate Dam-Danube River-Black Sea)

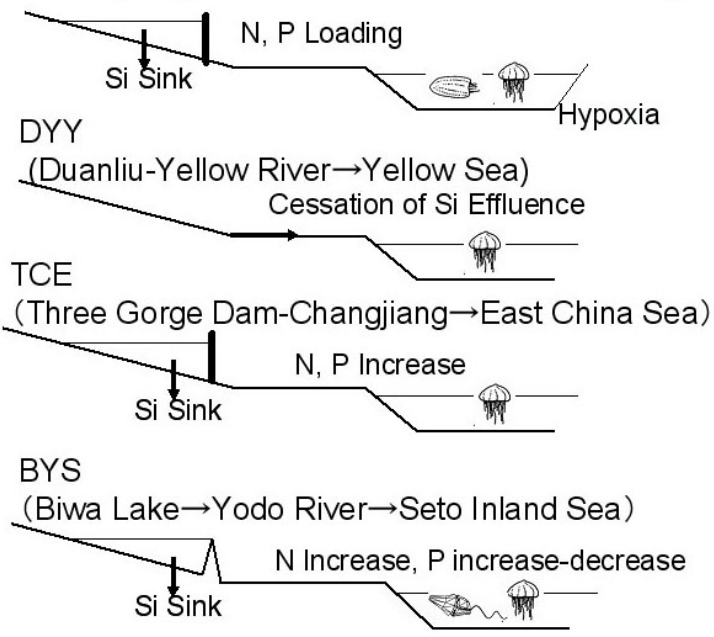

Fig.1 Four aquatic continua to be considered. Various types of silica retentions exist. 
than around $2 \mu \mathrm{M}^{5}$.

This hypothesis concerns the whole aquatic continuum (catchments, reservoirs or lakes, rivers and the coastal seas downstream) and very inter-disciplinary covering the chemical, biological and physical factors. A characteristic case was illustrated for the aquatic continuum of Irongate dam - Danube River - the Black Sea ${ }^{3}$ (abbreviated as IDB continuum in Fig.1), where the HABs of nonsiliceous algae increased after the construction of the dam in the early 1970s. The possibility of the similar tendency has been pointed out for the other aquatic continua.

In TCE (Three Gorge Dam - Changjiang - the East China Sea), flow-down of DSi is considered to be and have been retained in the dams ${ }^{6}$. The cessation of the water in the lower part of the Yellow River (Duanliu phenomenon) ${ }^{7), 8)}$ has been a significant issue. This would reduce the absolute supply of DSi to the Yellow sea (DYY continuum in Fig.1) more than the decrease of the ratio of DSi to $\mathrm{N}$ or $\mathrm{P}$. The ecological changes in these seas are not confined to the increase of HABs. In IDB, comb jelly fish increased, which has been attributed to the eutrophication, invasion of alien species, fisheries pressure to fish competing with jelly fish, climate change, and etc. In DYY and TCE, a giant jellyfish is increasing.

Silica deficiency may be less probable in Japan inherently because of the shortness of rivers as well as the lithological reasons that the geological feature is more volcanic than Europe ${ }^{9), 10)}$. Also, the supply of DSi is inherently larger due to the combination of the monsoonal rainfall and the higher temperature compared to Europe. Among the Japanese reservoirs (and lakes), the residence time of water in Lake Biwa is exceptionally large (around 5 years). Therefore, there is a possibility of similar phenomenon in BYS (Lake Biwa - Yodo River - the Seto Inland Sea) together with the increased $\mathrm{N}$ and $\mathrm{P}$ loadings ${ }^{11)}$.

While the retention of DSi in a eutrophicated large reservoir have been confirmed in most of the cases, consequent changes in marine ecosystem are not clarified well mainly because of the lack of data that should ideally be time-series of the set of nutrients and algal compositions. Particularly, the data from the East Asian sea are insufficient in spite of the importance of this area, where the economical growth is largest in the world. The BYS could be a proxy and a proceding model of the characteristic East Asian system in that it experienced a rapid economic growth in $1960 \mathrm{~s}^{11)}$.

Here we seek for another aspect infered in this hypothesis other than the shift from benign algae to harmful ones. The diatom bears the most part in the role of "biological pump", which draws down the organic matter converted from the inorganic nutrients in the upper layer to the lower layer and finally to the sediments by sinking after the spring bloom. This

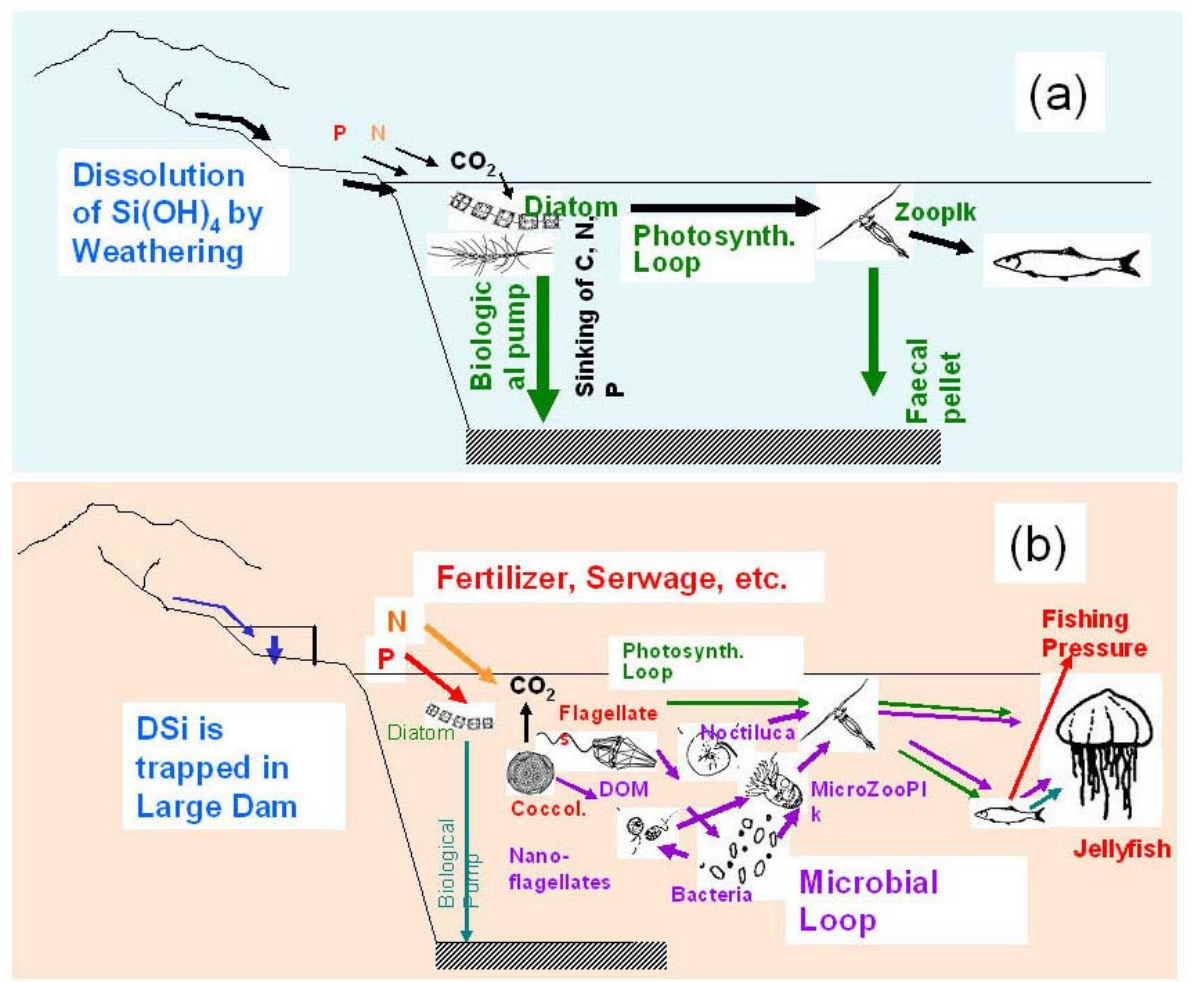

Fig.2 Schematic diagram of biogenic fluxes of substances in the coastal seas (a) with less anthropogenic effects and (b) with the human perturbation in the ratio of N: P: Si discharges. 
contributes to remove the substances related to the eutrophication and even to the global warming (Fig.2 (a)).On the contrary, non-diatom algae do not sink remarkably as the diatom and therefore the rate of biological pump by them is lower. Some of the latter algae "recycle" nutrients quickly within the upper layer or taking out the nutrients in the lower layer by their vertical migration. Therefore, the decline of DSi would let the surplus $\mathrm{N}$ and $\mathrm{P}$ and biogenic substances after the spring bloom be retained in the upper layer and contribute substantially to the eutrophication (Fig.1 (b)).

Evidence for above extended hypothesis is not plenty yet. However, a study based on the field mezocosm experiment has estimated that the addition of $1 \mathrm{~g}-\mathrm{Si}$ into the Si-depleted seawater enhanced the diatom production and sinking flux of POM (particulate organic matter) by $3.7 \mathrm{~g}-\mathrm{C}^{12)}$.

Since various processes are involved in this hypothesis, review of existing researches working with plural aquatic continua and construction of relatively simplified model shown in the next section would be appropriate in order to gradually reduce the scientific uncertainties.

\section{METHOD}

\section{(1) Observation}

As for the BYS, we have been collecting existing data as well as performing a long-term, biogeochemical monitoring in the Seto Inland Sea using ferry boats ${ }^{13)}$ (Fig.3). It has been confirmed that around $70 \%$ of entering DSi was retained in Lake Biwa. In the Seto Inland Sea, absolute concentrations of DIN, DIP and DSi in the surface layer were higher in the east reflecting the direct loading of $\mathrm{N}$ and $\mathrm{P}$ from Osaka area and inflow of DSi from Yodo River (Fig.4). However, the DSi/DIN ratio was lower in the east possibly because of the retention of DSi in Lake Biwa and further uptake by diatom in Osaka Bay enhanced by $\mathrm{N}$ and $\mathrm{P}$ inputs.

The records on red tide outbreaks by Fisheries Agency showed that number of the "diatom red tides" was higher in the sub-basin 7 and that of the "flagellates red tides" was higher in the sub-basin 6, for the following reason. Diatom dominates where none of nutrients limits the growth and flagellates dominates where the growth of diatom is limited anyhow. Consequently, the flagellates red tides occurs in the sub-basin 6, where DSi/DIN is low to some extent and growth of the diatom may sometimes limited by the lower absolute concentration of DSi. The red tide records showed another important point that the flagellates red tides occurs mainly in summer, which would not be explained solely by the condition of nutrients. These observational facts are used to tune the model.

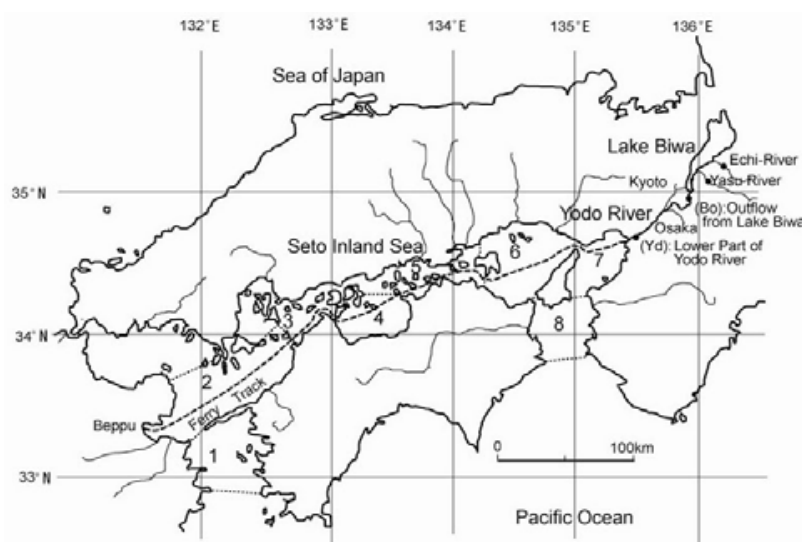

Fig.3 Map of the BYS (Lake Biwa - Yodo River - the Seto Inland Sea) aquatic continuum and the ferry route used to long-term monitoring. The number 1 to 8 denotes the each sub-basin.

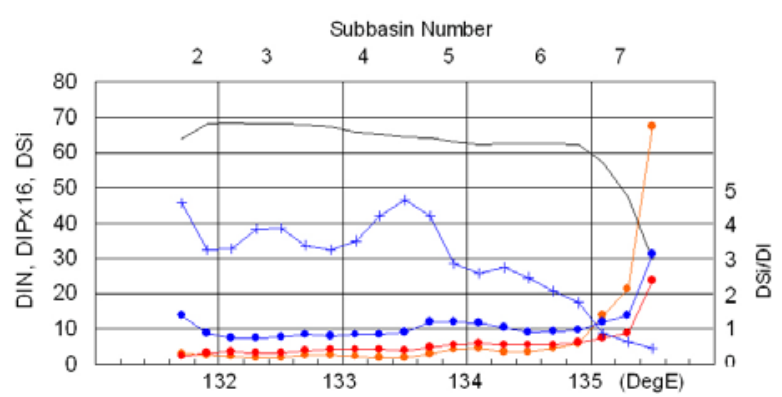

Fig.4 Distribution of DIN (orange dot), DIPx16 (red dot), DSi (blue dot), DSi/DIN (blue cross) and salinity (black line) in the surface water of the Seto Inland Sea. Sub-basin numbers 2 to 7 correspond to those in Fig.3. Outbreaks of "diatom red tides" and "flagellates red tides" are higher in the sub-basin 7 and 6, respectively. This figure was reproduced from $\operatorname{Ref}^{11)}$ with permission from

\section{(2) Model}

The model is 1-box and time-dependent representing the upper layer of the estuary (Fig.5). It is hereafter abbreviated as MSFT-Model (Marine Stoichiometric and Functional Type Model), considering N: P: Si stoichiometry and the two "functional types" of algae: Diatom (silicifier and fast sinker) and Flagellates (non-silicifier and slow sinker). The compartments are named with the capital letter so as to imply the functional type generically rather than a specific term of organisms.

The Diatom and Flagellates perform primary production being regulated by the Liebig's law on $\mathrm{N}$, $\mathrm{P}$ and Si. Some portion of them falls down with the sinking rates, which is converted from the sinking speed to the rate how much portion is removed from upper layer per day. The Zooplk grazes these two algae and the MicroZooplk at the rates expressed by 
the maximum grazing rates, the half saturation constants and the preference rates specified for these three preys. The Jellyfish hunts Zooplankton. Micro-zooplankton hunts Bacteria, which take $\mathrm{DOM}_{1,2}$ (dissolved organic matters, subscripts 1 and 2 denote "labile" and "refractory", respectively). The detritus, which is the difference between the uptake and growth of each organisms, are exported to the four compartments, $\mathrm{DOM}_{1,2}, \mathrm{POM}_{1,2}$ (particulate organic matters), with certain allocation factors proposed in BIOGEN model developed for the Black Sea ${ }^{14)}$. Working variable is the carbon (unit: $\left.\mathrm{mg}-\mathrm{Cm}^{-3}\right)$. The fluxes of N, P and Si are calculated so as to accompany the carbon fluxes through the algal compartments following the Redfield ratio. The external parameters such as the inputs of DIN, DIP and DSi and the flush out rates are determined from the dimensions of given aquatic continua.

The model was coded with Stella software and the prototype of the model was constructed referring to the NPZD (Nutrient - Phytoplankton - Zooplankton Detritus) model by Kemp et al. ${ }^{15)}$. Parameters on the trophic interactions such as nutrient and DOM uptakes, grazing, predation, biodegradation have been derived from the existing works.

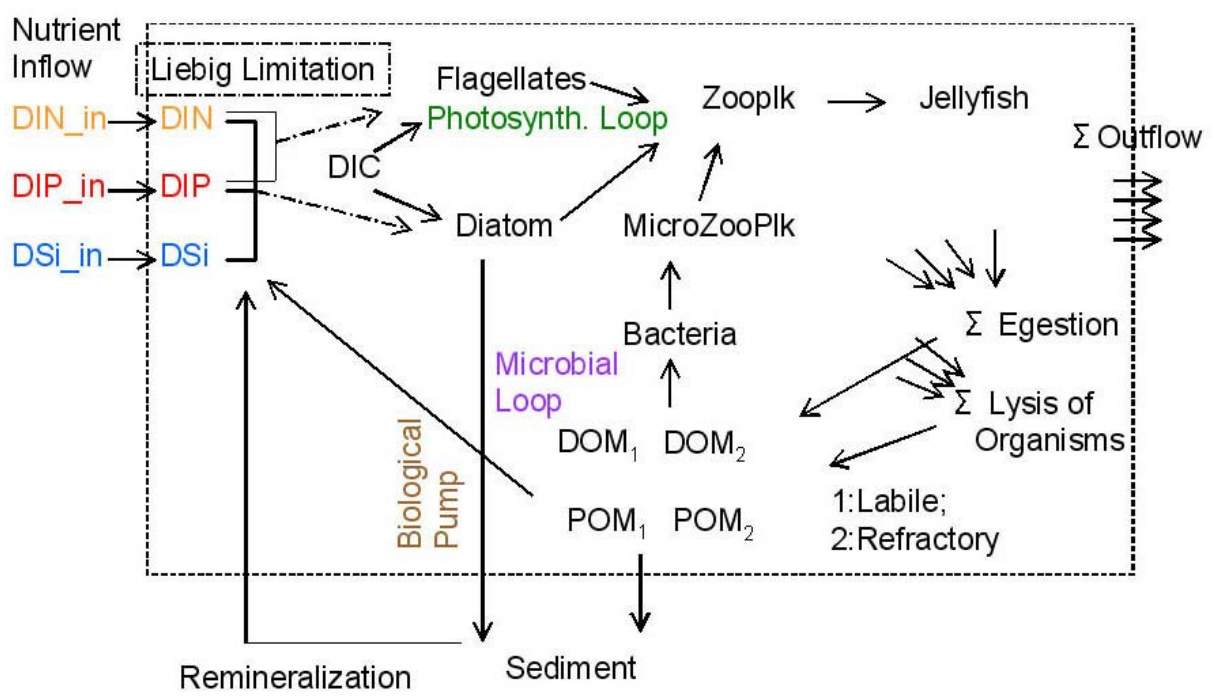

Fig.5 A schematic flow diagram of the marine ecological model dveloped in this study.

\section{RESULTS}

Several cases of runs were performed by changing the parameters on the nutrient inputs and flush-out. In the case of fig.6, the sinking rate for Diatom and Flagellates were $2 \%$ day $^{-1}$ and $0.2 \%$ day $^{-1}$, respectively. Shown are the temporal change in the biomasses of diatom and flagellates and three nutrients for 100 days starting from the initial condition assuming the winter, when nutrients are replete and the plankton biomasses are small. The factor 16 on DIP is to even the effects of three nutrients in terms of the Redfield ratio.

During the first 10 days, Diatom and Flagellates increased rapidly taking up the initial nutrients. This phase corresponds to the spring bloom. These blooms stopped due to the depletion of nutrients. In this case, DIN depleted in the first place and primarily stopped the bloom. Then the Zooplankton increased grazing the algal biomasses. After the end of spring bloom, certain levels of both algae were maintained by continuous inputs of nutrients.

In this case, the difference in the sinking rate between Diatom and Flagellates $\left(2 \%\right.$ and $0.2 \%$ day $^{-1}$, respectively) caused no remarkable difference in the composition of two algae. This was because the grazing pressure overwhelmed the sinking of both algae. This result does not coincide to the observational facts that the flagellates red tides increase in summer replacing the diatom.

To improve the model, we refer to the culture experiments by Bienfang et al. ${ }^{16)}$, who observed the sinking velocity of diatoms and showed that they accelerate the sinking speed when the nutrients, particularly DSi, were depleted and that increased sinking speed continued even after the nutrients were added.

Considering this result, the sinking rate of Diatom was increased to $20 \%$ day $^{-1}$ when any nutrient falls below the half saturation constants and this fast 
sinking continues even after the level of nutrient is recovered (Fig.7). In this case, composition of diatom drastically decreased after the depletion of nutrients and never recovered. Once the Diatom decreased DSi
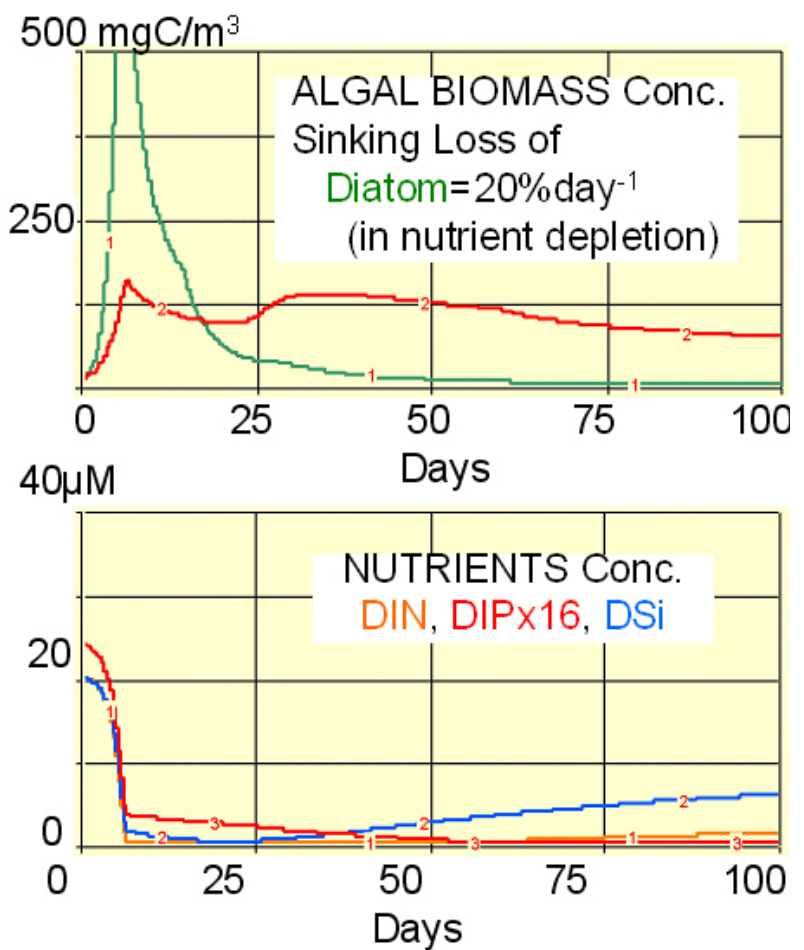

Fig.6 A model result on the variation of two algae (top) and nutrients (below).
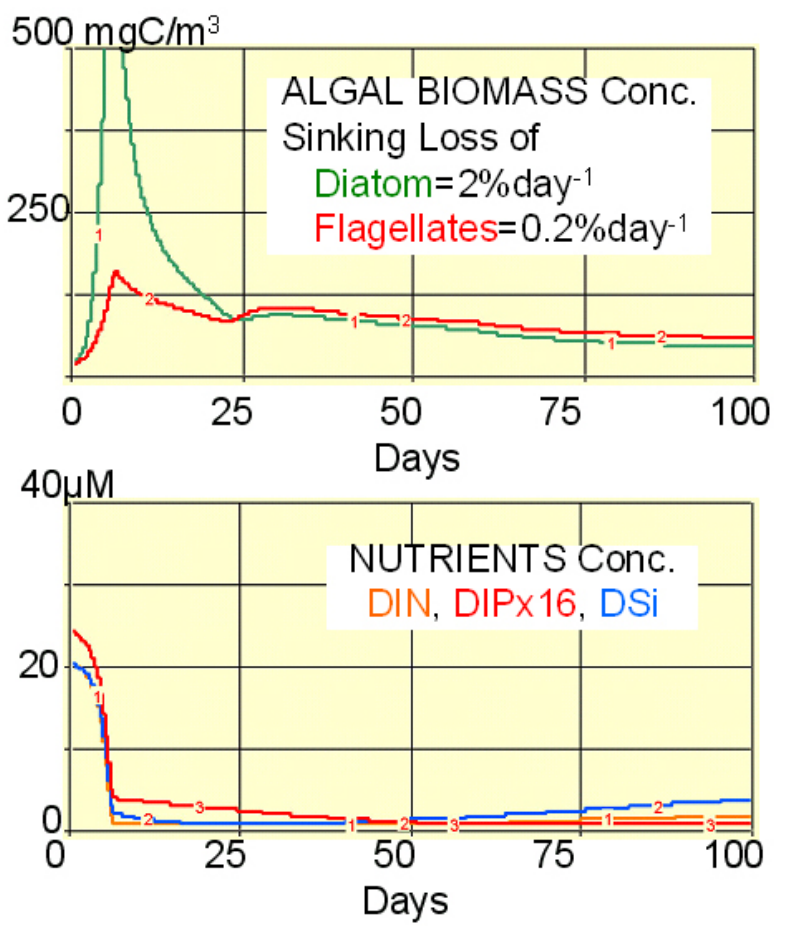

Fig.7 Results of a case, where the sinking rate of diatom is set to be largerafter the nutrient depletion, shown in the same way of the former figure. increased because of its constant input and absence of Diatom (Fig.7). As a matter of course, the downward biological pump diminished in the absence of Diatom even some nutrients were constantly given. These surplus $\mathrm{N}$ and $\mathrm{P}$ fueled the growth of the Flagellates, which remain in the upper layer and continue to feeding the summer food web instead of sinking.

Thus, consideration of the sinking process of diatom would explain the apparent contradiction to the silica deficiency hypothesis in the observational results that the flagellates red tide is higher in summer when the $\mathrm{DSi} / \mathrm{DIN}$ ratio is rather higher.

\section{CONCLUSIONS AND DISCUSSIONS}

It has been confirmed that the increase of eutrophicated still waters on land tends to trap the supply of Si to the coastal seas. It is not easy, however, to straightforwardly explain the dominant algal group based solely on the N: P: Si stoichiometric ratio. Results of our model, although they are still preliminary, infer that consideration of the behavioral factors specific to each algal group would supplement the explanation. Sinking characteristics, which is different between diatom and other algae and between the nutrients replete and deplete conditions, is one of these factors.

Silicification and sinking of diatom are indivisible because the success of the diatom in the marine ecosystem seems to be due largely to the strategy of generating frustules of biogenic silica, which functions not only as the armor but also as the ballast ${ }^{17}$. In this regard, the silica deficiency hypothesis should evolve to the extended one, which takes the sinking characteristics into account.

Following speculations, most of which are quoted from the review work by Tett et al. ${ }^{18)}$ would further clarify the reasons why the stoichiometric ratio of the seawater does not correlate with the dominant algae,

Firstly, the stoichiometric composition of diatoms often deviate from the Redfield ratio and the diatom is rather tough in the environment of low DSi. Secondly, the micro algae are not always pure photo-autotrophs and have several other trophic paths such as the heterotrophy, the mixotrophy and some metabolism to take in the dissolved organic matter. Also, some of them can take nutrients in the other occasion or location, e.g., by reserving nutrients as cell quota obtained while nutrients are replete (luxury uptake) or take the nutrients of lower layer by the vertical migration.

Another factor is that the anthropogenic shift of biogeochemical condition is confined to the coastal area and the shelf processes are rather subject to the processes synchronized to the outer ocean. 
In spite of these difficulties to get the visible evidence, it is worth studying these matters since the anthropogenic perturbations against the natural the cycle of N, P and Si and the deterioration of coastal ecosystems are getting significant globally.

ACKNOWLEDGMENTS: The author thanks to Kansai-Kisen Co. Ltd. for letting us to use their ferryboats for long-term monitoring and to Professor W. M. Kemp for providing their model for us to develop the model. This study was supported by the Global Environment Research Fund of the Ministry of Environment (Grant No. D3 and D061).

\section{REFERENCES}

1) Officer, C. B. and Ryther, J. H.: The possible importance of silicon in marine eutrophication, Mar. Ecol. Prog. Ser., Vol. 3, pp. 83-914, 1980.

2) Billen, G., Lancelot, C. and Meybeck, M.: N, P, Si retention along aquatic continuum from land to ocean, Mantoura R. F. C et al. (eds.), Ocean Margin Processes in Global Change, pp.19-44, Wiley, 1991.

3) Humborg, C., Ittekkot, V., Cociasu, A. and von Bodungen, B.: Effect of Danube River dam on Black Sea biogeochemistry and ecosystem structure, Nature, 27, 385-388, 1997.

4) Ittekkot, V., Humborg, C. and Schafer, P.: Hydrological alterations and marine biogeochemistry: A silicate issue? Bioscience, Vol. 50, pp. 776-782, 2000.

5) Egge, J. K. and Aksnes, D. L.: Silicate as regulating nutrient in phytoplankton competition, Mar. Ecol. Prog. Ser., Vol. 83, pp. 281-289, 1992.

6) Wang, B.: Cultural eutrophication in the Changjiang (Yangtze River) plume: History and perspective, Estuar. Coast. and Shelf Sc., Vol. 71, pp. 3-12, 2006.

7) Chen, J., He, D. and Cui, S.: The response of river water quality and quantity to the development of irrigated agriculture in the last 4 decades in the Yellow River Basin, China, Water Resour. Res. 39, 1047, doi: 10.1029/2001 WR001234, 2003.

8) Wang, H., Yang, Z., Saito, Y., Liu, J. P. and Sun, X.: Interannual and seasonal variation of the Huanghe (Yellow River) water discharge over the past 50 years: Connections to impacts from ENSO events and dams, Global and Planetary Change, Vol. 50, pp. 212-225, 2006.

9) Hartmann, J. and Kempe, S.: Geochemistry of the River Rhine and the upper Danube: Recent trends and lithological influence on baselines, (to appear).

10) Hartmann, J., Jansen, N. and Kempe, S.: High riverine fluxes of dissolved silica from Japan - the influence of lithology, Geophysical Research Abstracts, EGU2007-A-00861, Vienna, 2007.

11) Harashima, A., Kimoto, T., Wakabayashi, T. and Toshiyasu, T.: Verification of the silica deficiency hypothesis based on biogeochemical trends in the aquatic continuum of Lake Biwa - Yodo River - Seto Inland Sea, Japan, Ambio, Vol. 35, pp. 185-204, 2006.

12) Wassmann, P., Egge, J., Reigstad, K. M. and Aksnes, D. L.: Influence of dissolved silicate on vertical flux of particulate biogenic matter, Mar. Poll. Bull., Vol. 33, pp. 10-21, 1996.

13) Harashima, A., Tsuda, R., Tanaka, Y., Kimoto, T., Tatsuta, H. and Furusawa, K.: Monitoring algal blooms and related biogeochemical changes by a flow-through system deployed on ferries in the adjacent seas of Japan, in Kahru, M. et al. (eds.) : Monitoring Algal Blooms, Springer, pp. 85-112, 1997.

14) Lancelot, C., Staneva, J., Van Eeckhout, D., Beckers, J.-M. and Stanev, E.: Modeling the Danube-influenced northwestern continental shelf of the Black Sea. II: Ecosystem response to changes in nutrient delivery by the Danube River after its damming in 1972, Estuar. Coast. and Shelf Sc., Vol. 54, pp. 473-499, 2002.

15) Kemp, W. M., Brooks, M. T. and Hood, R. R.: Nutrient enrichment, habitat variability and trophic transfer efficiency in simple models of pelagic ecosystems, Mar. Ecol. Prog. Ser., Vol. 223, 73-87, 2001.

16) Bienfang, P. K., Harrison, P. J. and Quarmby, L. M.: Sinking rate response to depletion of nitrate, phosphate and silicate in four marine diatoms. Mar. Biol., Vol. 67, pp. 295-302, 1982.

17) Raven, J. A. and Waite, A. M.: The evolution of silicification in diatoms: inescapable sinking and sinking as escape? New Phytologist, Vol. 162, pp. 45-61, 2004.

18) Tett, P., Hydes, D. and Sanders, R.: Influence of nutrient biogeochemistry on the ecology of northwest European shelf seas, in Black, K. D. et al. (eds.) : Biogeochemistry of Marine Systems, pp. 293-363, Sheffield Academic Press, 2003.

(Received February 7, 2007) 